\title{
Cognac Polyphenolic Compounds Increase Bradykinin-Induced Nitric Oxide Production in Endothelial Cells
}

\author{
A. SALL DiALlO ${ }^{2}$, M. SARR ${ }^{1,2}$, H. A. MOSTEFAI ${ }^{1}$, N. CARUSIO ${ }^{1}$, M. PRICCI ${ }^{1}$, \\ R. ANDRIANTSITOHAINA ${ }^{1}$
}

${ }^{1}$ INSERM, U771, CNRS, UMR 6214, Université d'Angers, Faculté de Médecine, Biologie NeuroVasculaire Intégrée, Angers, France, ${ }^{2}$ Laboratoire de Physiologie Pharmaceutique, Faculté de Médecine, de Pharmacie et d'Odontostomatologie, UCAD, Dakar, Senegal

Received August 2, 2007

Accepted October 5, 2007

On-line November 30, 2007

\begin{abstract}
Summary
We recently reported that in vitro Cognac polyphenolic compounds (CPC) induce NO-dependent vasorelaxant effects and stimulate cardiac function. In the present study, we aim to investigate the effect of CPC on both nitric oxide (NO) and superoxide anions $\left(\mathrm{O}_{2}^{-}\right)$production in cultured human endothelial cells. In addition, its effect on the bradykinin (BK)-induced NO production was also tested. The role and sources of $\mathrm{O}_{2}^{-}$in the concomitant effect of BK plus CPC were pharmacologically determined. $\mathrm{NO}$ and $\mathrm{O}_{2}^{-}$signals were measured using electron paramagnetic resonance technique using specific spin trappings. Both, CPC and BK induced an increase in NO production in human endothelial cells. The combination of both further enhanced NO release. The capacity of CPC plus BK to increase NO signal was blunted by the NO synthase inhibitor, $\mathrm{N}^{G}$-nitro-Larginine methyl ester, and was enhanced in the presence either of superoxide dismutase or catalase. Moreover, CPC plus BK response was greater after inhibition of either NADPH oxidase by apocynin or xanthine oxidase by allopurinol but it was not affected by rotenone. CPC did not affect $\mathrm{O}_{2}^{-}$level either alone or after its increase upon lipopolysaccharide treatment. Finally, the capacity of BK alone to increase NO was enhanced either by apocynin or allopurinol. Altogether, these data demonstrate that $\mathrm{CPC}$ is able to directly increase NO production without affecting $\mathrm{O}_{2}^{-}$and enhances the BK-induced NO production in human endothelial cells. The data highlight the ability of BK to stimulate not only NADPH oxidase- but also xanthine oxidase-inhibitor sensitive mechanisms that reduce its efficiency in increasing NO either alone or in the presence of CPC. These results bring pharmacological evidence for vascular protection by CPC via its potentiating effect of BK response in terms of endothelial NO release.
\end{abstract}

\section{Key words}

Polyphenols • Bradykinin • Reactive oxygen species • Endothelial cells

\section{Corresponding author}

R. Andriantsitohaina, Laboratoire de Biologie Neuro-Vasculaire Intégrée UMR INSERM 771- CNRS 6214, Rue Haute de Reculée, 49045 Angers, France. Fax: + 3302417358 95. E-mail: ramaroson.andriantsitohaina@univ-angers.fr

\section{Introduction}

Endothelium-derived nitric oxide is a pivotal mediator involved in a variety of biological process, including regulation of smooth muscle tone and endothelium-dependent relaxation, platelet activation and aggregation, neurotransmission and vascular cells signaling (Randriamboavonjy and Fleming 2005, Busse and Fleming 2006, Moncada and Bolanos 2006, Moncada and Higgs 2006, Villalobo 2006). The production of NO from the endothelium can be increased by both pharmacological and physiological agonists (e.g. bradykinin) and this effect is dependent on the interaction of calcium/calmodulin with endothelial NO synthase (eNOS) (Boulanger et al. 1990, Schini-Kerth 1999, Bae et al. 2003, Schneider et al. 2003) - the PKA-dependent phosphorylation of eNOS (Bae et al. 2003). Interestingly, the mechanisms by which polyphenols can produce NO in endothelial cells, involve not only an increase in intracellular calcium, an activation of tyrosine kinases (Stoclet et al. 1999, Martin et al. 2002), 
and an up-regulation of eNOS mRNA (Nie et al. 2006), but also additional roles of reactive oxygen species (ROS) (Andriantsitohaina 1999, Jaimes et al. 2001, Ndiaye et al. 2005). However, the interpretation of the studies investigating vascular NO production stimulated by physiological or pharmacological agonists or plant polyphenols need to be considered. With regard to plant polyphenols, Cognac belongs to alcoholic drinks rich in polyphenols and moderate consumption may have potential beneficial effects on health. We recently reported that oral treatment with CPC appears to have no in vivo impact on blood pressure, heart rate of the rats or on cardiac contractility ex vivo, but it reduces heart work and decreases the infarct size after ischemia-reperfusion (Ralay Ranaivo et al. 2004). However, the effects of Cognac polyphenolic compounds (CPC) on production of NO in cultured human aortic endothelial cells, as well as their effect on the capacity of bradykinin, a physiologically active peptide and potent endothelium-dependent vasodilator, to stimulate the release of NO have not been investigated yet. Accordingly, we sought to evaluate the interactions and relationships between bradykinin, and $\mathrm{CPC}$ on the production of $\mathrm{NO}$ in human endothelial cells. Finally, based on our previous studies on red wine polyphenolic compounds (RWPC) with different polyphenol composition (Andriambeloson et al. 1998, Martin et al. 2002), it was intended to test the exclusivity and specificity of CPC on human endothelial cells.

\section{Methods}

\section{Cell culture}

EAhy 926 cells, a cell line derived from human umbilical vein endothelial cells, were cultured in growth medium (DMEM, Ham's F-12, 1:1) supplemented with $1 \%$ 1-glutamine, $1 \%$ HAT, $1 \%$ NEAA, $1 \%$ Na-pyruvate, $1 \%$ streptomycin/penicillin (Cambrex, Verviers, Belgium), and $10 \%$ FBS (Invitrogen, Cergy Pontoise, France). All experiments were performed in confluent EAhy cells from passages 8 to 12 serumdeprived for at least $24 \mathrm{~h}$.

For the measurement of NO level, the culture medium was removed and replaced by fresh Hank's Balanced Salt Solution (HBSS), pH 7.4, containing $1 \mathrm{M} \mathrm{N}$ 2-hydroxythylpiperazine-N9-2-ethane-sulfonic acid (HEPES), $1 \mathrm{M} \mathrm{L}$-arginine, $1 \mathrm{M} \mathrm{CaCl}_{2}$ and $0.1 \%$ BSA. After $60 \mathrm{~min}$, cells were treated with bradykinin (BK, $40 \mu \mathrm{M}$, Sigma-Aldrich, Saint Quentin, Fallavier, France), alone or $15 \mathrm{~min}$ prior treatment of CPC $(0.03 \mathrm{mg} / \mathrm{ml}$ in 0.5
$\%$ glucose) for $30 \mathrm{~min}$. CPC was used at a concentration at which it produced maximal relaxation of aortic rings with functional endothelium (Ralay Ranaivo et al. 2004).

Parallel sets of experiments were performed in the presence of of either superoxide dismutase, (SOD, 100 $\mathrm{UI} / \mathrm{ml})$, catalase $(100 \mathrm{UI} / \mathrm{ml})$, the xanthine oxidase inhibitor, allopurinol (50 $\mu \mathrm{M}$, Sigma-Aldrich), the potent NADPH oxidase inhibitor, apocynin $(100 \mu \mathrm{M}$, SigmaAldrich), the mitochondrial complex I inhibitor, rotenone (5 $\mu \mathrm{M}$, Sigma-Aldrich) or the NOS inhibitor, nitro-Larginine (L-NAME, $100 \mu \mathrm{M}$, Sigma-Aldrich).

For the measurement of superoxide anions $\left(\mathrm{O}_{2}^{-}\right)$ level, cells were treated with lipopolysaccharide (LPS, $10 \mu \mathrm{g} / \mathrm{ml}$, Sigma-Aldrich) for $3 \mathrm{~h}$ and then with or without CPC $(0.03 \mathrm{mg} / \mathrm{ml}$ in $0.5 \%$ glucose $)$ for further $60 \mathrm{~min}$.

NO spin trapping and electronic paramagnetic resonance (EPR) studies

Detection of NO production was performed using the technique with $\mathrm{Fe}^{2+}$ diethyldithiocarbamate (DETC, Sigma-Aldrich) as spin trap. Briefly, after $30 \mathrm{~min}$ of CPC treatment in the absence or presence of different inhibitors, the medium was replaced with $250 \mu \mathrm{l}$ of Krebs Hepes Buffer (KHB), and then treated with $250 \mu 1$ of colloid $\mathrm{Fe}(\mathrm{DETC})_{2}$ and incubated for $45 \mathrm{~min}$ at $37{ }^{\circ} \mathrm{C}$. NO signal was measured in situ by EPR.

NO measurement was performed on a table-top $\mathrm{x}$-band spectrometer Miniscope (Magnettech, MS200, Berlin, Germany). Recordings were made at $77^{\circ} \mathrm{K}$, using a Dewar flask. Instrument settings were $10 \mathrm{~mW}$ of microwave power, $1 \mathrm{mT}$ of amplitude modulation, $100 \mathrm{kHz}$ of modulation frequency, $150 \mathrm{~s}$ of Sweep time and 5 scans. Signals were quantified by measuring the total amplitude, after the correction of baseline as previously described (Agouni et al. 2008). The quantitative measurement of the NO-Fe(DETC $)_{2}$ signal amplitude was reported to the relative units for protein concentration of cells and results are given as \% of control.

\section{Determination of superoxide anion generation}

For the detection of superoxide anion production, EAhy 926 cells were incubated for $45 \mathrm{~min}$ at $37{ }^{\circ} \mathrm{C}$ in KHB (pH 7.4) containing $5 \mu \mathrm{M}$ DETC, $25 \mu \mathrm{M}$ deferoxamine and $500 \mu \mathrm{M} 1$ hydroxy-3 methoxycarbonyl 2,2,5,5-tetramethylpyrrolidin (CMH, Noxygen, Germany). Briefly, deferroxamin and DETC were dissolved under argon gas bubbling in ice-cold KHB. They were rapidly mixed to the $\mathrm{CMH}$ solution, which was used immediately. 
Then, cells were detached with trypsin-EDTA (Invitrogen, Cergy Pontoise, France) and frozen in plastic tubes to form rods. Electron spin resonance (ESR) spectra were recorded on a table-top $\mathrm{x}$-band spectrometer Miniscope (Magnettech). The ESR instrument settings were as follows: BO-field, $3327 \mathrm{G}$, microwave power, $1 \mathrm{~mW}(20$ $\mathrm{db}$ ), modulation amplitude, $5 \mathrm{G}$, sweep time, $60 \mathrm{~s}$, field sweep, 60 G (BO-sweep), gain 500 (5×2). Signals were quantified by measuring the total amplitude, after correction of baseline and normalization to the protein concentration of cells.

\section{CPC contents}

The enriched and lyophilized CPC powder was provided by the 'Bureau Interprofessionnel du Cognac' and contains, as previously described (Ralay Ranaivo et al. 2004) in $\mathrm{mg} / \mathrm{g}$ of powder: gallic acid, 2.28 , ellagic acid, 15.17, 5-hydroxy-methylfurfural, 0.17 , syringic acid, 0.74 , vanillin, 0.45 , syringaldehyde, 2.02, scopoletin, 0.03, coniferaldehyde, 2.35, sinapaldehyde, 8.21. The total polyphenols content was about $48.8 \%$ determined by colorimetric Follin-Ciocalteau method using gallic acid as standard.

\section{Statistical analysis}

All values are mean \pm S.E.M. $\mathrm{n}$ represents the number of experiments as appropriate. Statistical analysis was carried out using one-way ANOVA. A Fisher's PLSD test was used for post hoc comparison. $\mathrm{P}<0.05$ was considered to be statistically significant.

\section{Results}

\section{Effect of CPC on BK-induced NO production}

As illustrated on Figure 1, exposure of EAhy 926 endothelial cells to BK led to an expected increase in NO production $(+32 \pm 6.8 \%, \quad \mathrm{P}<0.05)$. CPC also significantly enhanced NO production $(+21 \pm 10.5 \%$ $\mathrm{P}<0.05)$ to the same extent as that triggered by BK. Coincubation of $\mathrm{CPC}$ with $\mathrm{BK}$ induced further increase in NO release $(+82 \pm 8 \%, \mathrm{P}<0.01)$. The capacity of CPC plus BK in increasing NO signal was blunted by the NOS inhibitor, L-NAME $(-22 \pm 7.7 \%, \mathrm{P}<0.05)$.

\section{Enhancement of NO production after inhibition of either} NADPH oxidase or xanthine oxidase system

As shown on Figure 2A, SOD, which catalyses the reduction of $\mathrm{O}_{2}^{-}$to hydrogen peroxide $\left(\mathrm{H}_{2} \mathrm{O}_{2}\right)$, significantly enhanced $\mathrm{NO}$ production induced by $\mathrm{BK}$ plus

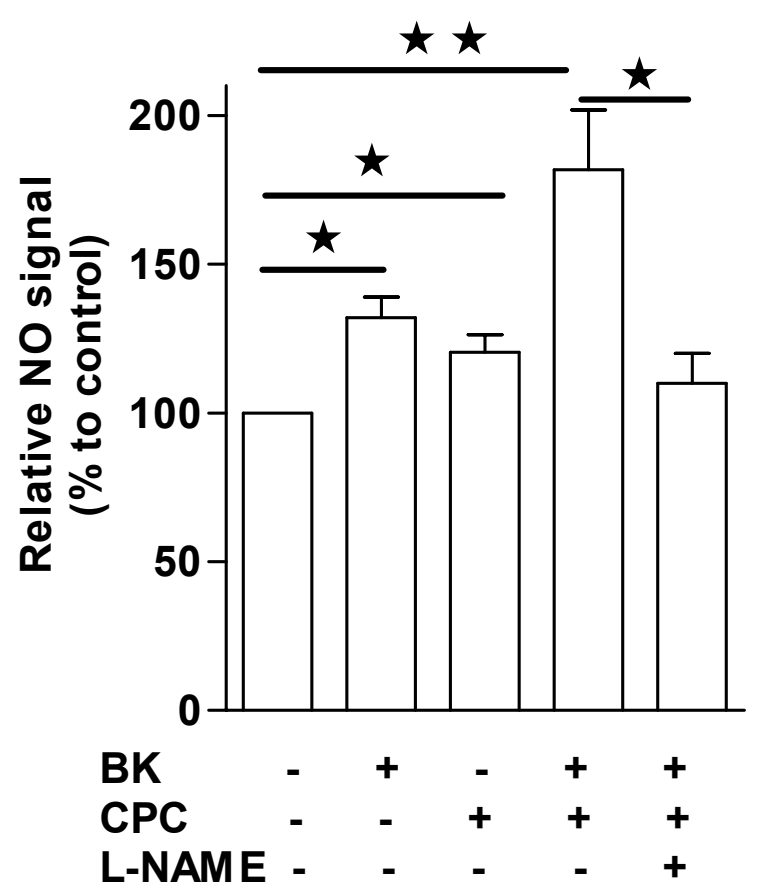

Fig. 1. Enhanced NO production in response to $B K$ and CPC was prevented by the nitric oxide synthase inhibitor, $\mathrm{N}^{\mathrm{w}}$-nitro-Larginine methyl ester, L-NAME. EAhy cells were pre-incubated with $40 \mu \mathrm{M}$ BK for $15 \mathrm{~min}$ before the treatment with CPC $\left(0.03 \mathrm{mg} / \mathrm{ml}, 0.5 \%\right.$ glucose) for $30 \mathrm{~min}$ at $37^{\circ} \mathrm{C}$ in the presence of $0.1 \mathrm{mM}$ L-NAME, remained present throughout BK and CPC incubation. After the addition of $\mathrm{Fe}$ (II)Diethyldithiocarbamate $(\mathrm{DETC})_{2}$ complex, EAhy cells were then incubated for $45 \mathrm{~min}$ for the detection of the electron paramagnetic resonance [Fe(II)NO(DETC $)_{2}$ ] complex by ESR. Results are expressed as the mean \pm S.E.M. of experiments performed in duplicate on 4 separate occasions. * $p<0.05 ; * * p<0.01$ (one-way ANOVA).

CPC $(+41 \pm 8 \%, \mathrm{P}<0.01)$. Moreover, catalase, which is known as an efficient enzyme for the conversion of $\mathrm{H}_{2} \mathrm{O}_{2}$ into water and oxygen, significantly increased $\mathrm{NO}$ production elicited by BK plus CPC $(+21 \pm 3.4 \%, \mathrm{P}<0.05)$. Altogether, these data strongly suggest the involvement of ROS in response to either BK and/or CPC that blunted the production of NO.

The sources of endogenous ROS were investigated by testing the effect of different pharmacological inhibitors (Fig. 2B). Blockade of either NADPH oxidase by apocynin $(+38 \pm 15.7 \%, \mathrm{P}<0.05)$ or the cellular xanthine oxidase by allopurinol $(+64 \pm 5.7 \%$, $\mathrm{P}<0.01)$ significantly enhanced NO production elicited by CPC plus BK. In contrast, the inhibitor mitochondrial respiratory chain at site I, rotenone, did not affect the response to both agents.

These results show that the additive effect of $\mathrm{CPC}$ and $\mathrm{BK}$ on NO production was blunted by the production of ROS sensitive to inhibitors of both NAPDH oxidase and xanthine oxidase. 

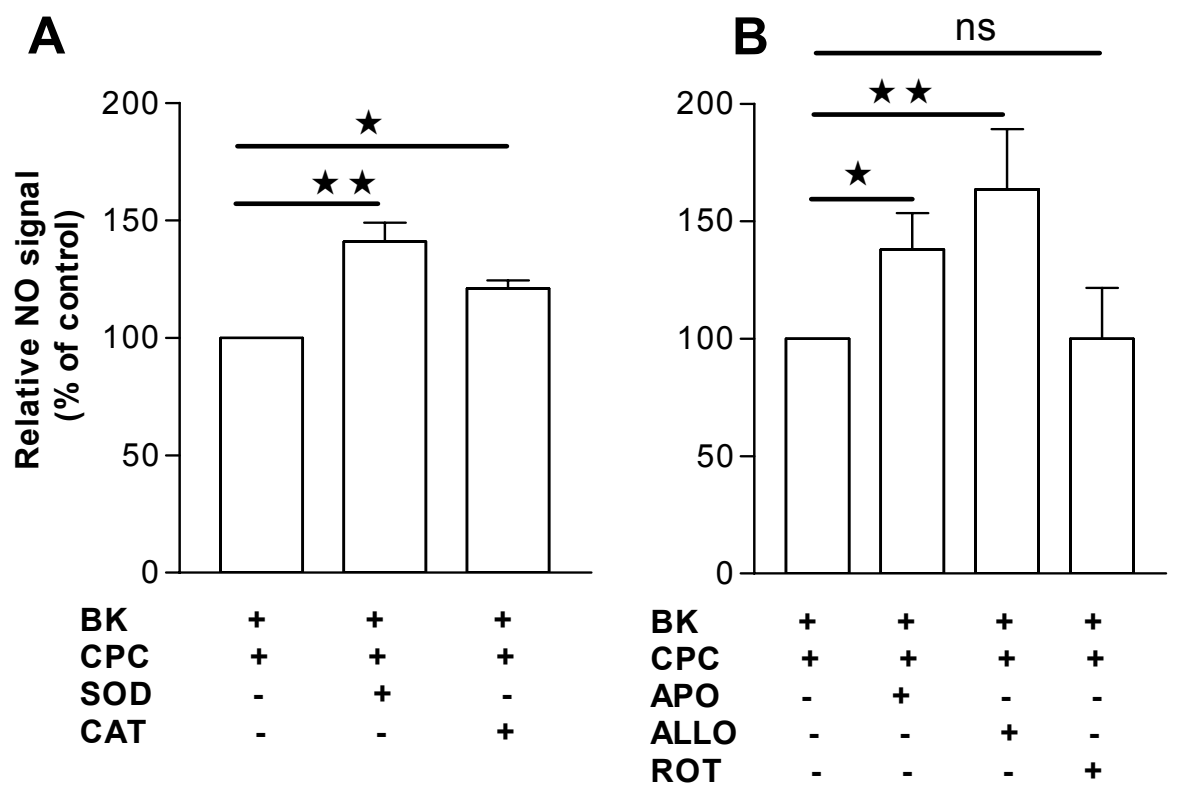

Fig. 2. (A) The potentiate NO production following BK and CPC exposure was enhanced by SOD and catalase. EAhy cells were preincubated with $40 \mu \mathrm{M} \mathrm{BK}$ for $15 \mathrm{~min}$ before the treatment with CPC $(0.03 \mathrm{mg} / \mathrm{ml}, 0.5 \%$ glucose $)$ for $30 \mathrm{~min}$ at $37^{\circ} \mathrm{C}$ in the presence of either $100 \mathrm{UI} / \mathrm{ml}$ SOD or catalase, which remained present throughout BK and CPC incubation. (B) The enhanced NO production following BK and CPC exposure was modulated by inhibitors of endogenous sources of ROS. EAhy cells were pre-incubated with $40 \mu \mathrm{M}$ BK for $15 \mathrm{~min}$ before the treatment with CPC $(0.03 \mathrm{mg} / \mathrm{ml}, 0.5 \%$ glucose $)$ for $30 \mathrm{~min}$ at $37{ }^{\circ} \mathrm{C}$ in the presence of either $50 \mu \mathrm{M}$ allopurinol (ALLO), $2 \mathrm{mM}$ apocynin (APO) or $5 \mu \mathrm{M}$ rotenone (ROT), which remained present throughout BK and CPC incubation. NO level was quantified after ESR measurement. Results are expressed as the mean \pm S.E.M. of experiments performed in duplicate on 4 separate occasions. ns, not significant; * $p<0.05 ; * * p<0.01$ (one-way ANOVA).
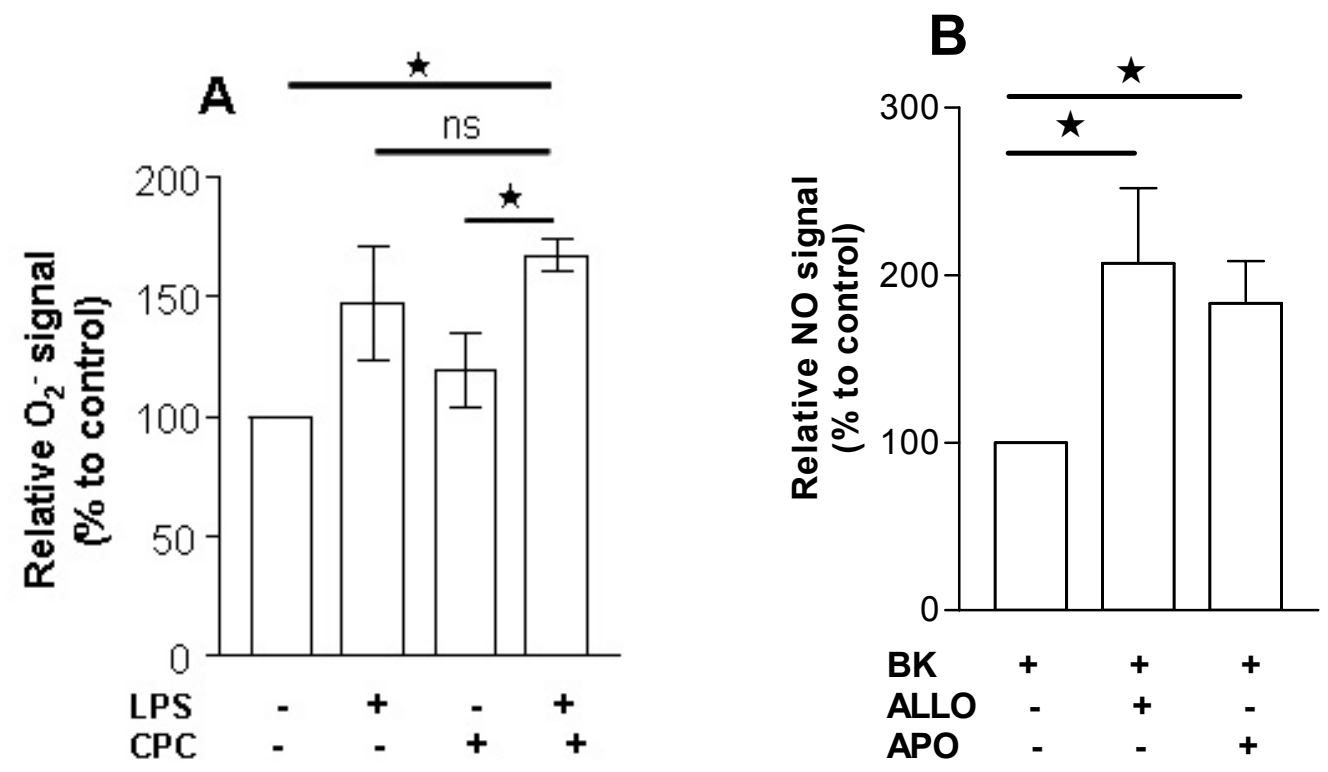

Fig. 3. (A) Enhanced $\mathrm{O}_{2}^{-}$production in response to LPS and CPC. EAhy cells were preincubated with $40 \mu \mathrm{M}$ BK for 15 min before the treatment with CPC $(0.03 \mathrm{mg} / \mathrm{ml}, 0.5 \%$ glucose $)$ for $30 \mathrm{~min}$ at $37^{\circ} \mathrm{C}$. After the addition of $\mathrm{CMH}$ solution, EAhy cells were then incubated for $45 \mathrm{~min}$ for the detection of the electron paramagnetic resonance CM-nitroxide complex by ESR. (B) The NO production following BK exposure was enhanced after inhibition of either NADPH oxidase or xanthine oxidase system. EAhy cells were incubated with $40 \mu \mathrm{M} \mathrm{BK}$ for $15 \mathrm{~min}$ before the treatment with $50 \mu \mathrm{M}$ allopurinol (ALLO) or $2 \mathrm{mM}$ apocynin (APO) for $30 \mathrm{~min}$ at $37^{\circ} \mathrm{C}$. NO level was quantified after ESR measurment. Results are expressed as the mean \pm S.E.M. of experiments performed in duplicate on 4 separate occasions. ns, not significant; * $\mathrm{p}<0.05$ (one-way ANOVA). 
Superoxide anions production originate from BK but not from CPC stimulation of endothelial cells

To test which compound used was able to promote $\mathrm{O}_{2}^{-}$production that blunted the increase of NO production elicited by addition of BK plus CPC, we directly measured either the capacity of CPC to increase $\mathrm{O}_{2}^{-}$or the effect of pharmacological inhibitors on BKinduced NO response in endothelial cells.

For the former (Fig. 3A), CPC alone was not able to significantly increase $\mathrm{O}_{2}^{-}$production under the experimental conditions used. This was not linked to the incapability of EAhy cells to produce $\mathrm{O}_{2}{ }^{-}$because the treatment of these endothelial cells with LPS resulted an increase of $\mathrm{O}_{2}^{-}$generation $(+47 \pm 23.4 \%, \quad \mathrm{P}<0.05)$. Moreover, the ability of LPS to increase $\mathrm{O}_{2}^{-}$was not significantly enhanced by concomitant treatment of the cells with CPC $(+67 \pm 6.5 \%)$. The increase in $\mathrm{O}_{2}^{-}$was abolished either by the superoxide mimetic MnTMPyP or by the cell-membrane permeable radical scavenger, tempol (data not shown).

Interestingly, the capacity of BK to increase NO production was significantly augmented in the presence of either apocynin $(+83 \pm 38.9 \%, \mathrm{P}<0.05)$ or allopurinol $(+107 \pm 45.1 \%, \mathrm{P}<0.05$, Fig. 3B).

\section{Discussion}

This present study provides new findings on the interaction between BK, a physiologically active peptide of the kinin group, and polyphenols from a non-alcoholic extract of cognac. Altogether, our data demonstrate that BK was able to stimulate NADPH oxidase- and xanthine oxidase-inhibitor sensitive mechanisms that reduced its efficiency in increasing NO either alone or in the presence of CPC. They also highlight the fact that CPC enhanced NO production without an effect on ROS production.

In human endothelial cell line, NO release is significantly modulated by interaction of BK and CPC, following activation of NO synthase and enzymes that generate intracellular $\mathrm{O}_{2}{ }^{-}$. Indeed, the data demonstrate that $\mathrm{CPC}$ is able to directly increase NO production without affecting $\mathrm{O}_{2}^{-}$and enhances the capacity of BK to produce NO in human endothelial cells. Our data elucidate the ability of BK to stimulate not only NADPH oxidase- but also xanthine oxidase-inhibitor sensitive mechanisms that reduce its efficiency in increasing $\mathrm{NO}$ either alone or in the presence of CPC.

The mechanisms by which BK and other endogenous vasoactive substances such as acetylcholine or adenosine, stimulate NO production in vascular tissues have been extensively described. They include a transient phosphorylation of the $\mathrm{B}_{2}$ receptor on tyrosine residues in cultured endothelial cells (Marrero et al. 1999), a calcium-store-dependent calcium influx as well as a PI3kinase activation (Kitayama et al. 2000, Schneider et al. 2003) (Tran et al. 2000) and a protein kinase Adependent phosphorylation of eNOS-Ser(1179) (Bae et al. 2003).

The role of ROS in BK-induced NO release is of particular interest. In bradykinin-stimulated coronary arteries, antisense oligonucleotides against CYP 2C (a cytochrome $\mathrm{P} 450$ isozyme homologous) potentiated NOmediated relaxation (Fleming et al. 2001). Folates, $\mathrm{O}_{2}^{-}$, and peroxynitrite scavengers restore the NO-generating activity of eNOS, collectively suggesting that extracellular cellular redox state plays an important role in NO-generating function of this enzyme (Zhang et al. 2000). In porcine aortic endothelial cells, Jaimes et al. (2001) have reported that $\mathrm{H}_{2} \mathrm{O}_{2}$ impairs $\mathrm{NO}$ production in response to both receptor-dependent and receptorindependent agonists and that these effects are due, at least in part, to inactivation of eNOS cofactors, whereas $\mathrm{HOCl}$ inhibits NO production by interfering with receptor-operated mechanisms at the level of the cell membrane. Furthermore, endogenous $\mathrm{H}_{2} \mathrm{O}_{2}$ derived from $\mathrm{NAD}(\mathrm{P}) \mathrm{H}$ oxidase, mediates endothelial $\mathrm{NO}$ production in response to another agonist such as angiotensin II in bovine aortic endothelial cells (Cai et al. 2002). In the present study, we demonstrated in human endothelial cells that the capacity of BK in increasing NO production was blunted by its ability to activate both NADPH oxidase- and xanthine oxidase-inhibitor sensitive mechanisms. Although, the two enzymes are known to enhance $\mathrm{O}_{2}^{-}$production in endothelial cells, especially after angiotensin II stimulation of NADPH oxidase. We report for the first time that BK can activate not only NADPH but also xanthine oxidase. It might be possible that $\mathrm{O}_{2}$-induced changes in the disturbance of cytosolic calcium homeostasis participate on the blunting effect of either NADPH or xanthine oxidase inhibitor on NO production elicited by BK. However, it is likely that $\mathrm{O}_{2}{ }^{-}$ produced by such enzymes interacts with $\mathrm{NO}$ to produce peroxynitrite and thus reduced NO bioavailability upon BK treatment.

With regard to $\mathrm{CPC}$, we reported that $\mathrm{CPC}$ induce a vasorelaxant response of rat aortic rings in the presence but not in the absence of functional endothelium 
suggesting the obligatory role of the endothelium (Ralay Ranaivo et al. 2004). The involvement of prostacyclin was unlikely as the vasorelaxant response to CPC was not altered in the presence of the cyclo-oxygenase inhibitor, indomethacin. However, the relaxant effect of CPC was totally abolished in the presence of the NO synthase inhibitor, L-NAME. These data suggest that endothelial relaxation of rat aorta by $\mathrm{CPC}$ involved NO-dependent pathway. The implication of NO could result from an increased production of $\mathrm{NO}$ or from a diminution of its breakdown. In the present study, we demonstrated that CPC was able to directly stimulate NO production from endothelial cells without affecting $\mathrm{O}_{2}^{-}$production. Thus, the ability of CPC to enhance endothelial NO production was not linked to its antioxidant properties. These results also contrast with our data with RWPC showing the involvement of $\mathrm{O}_{2}^{-}$in the cytosolic calcium increase evoked by these compounds leading to the activation of enzymes involved in the release of endothelial relaxant factors including eNOS (Martin et al. 2002, Duarte et al. 2004). Moreover, our results are not in accordance with the study showing that RWPC promotes the release of endothelial NO through the redox sensitive PI3/Akt pathway (Ndiaye et al. 2005). It is likely that the nature of polyphenols involved in the response to CPC and RWPC might explain the different mechanisms of these two compounds to promote NO release. For RWPC, the molecular identity of polyphenols responsible for this effect may include oligomeric condensed tannins and anthocyanins (Andriambeloson et al. 1998). Among the identified components of CPC, phenolic acids (gallic acid and vanillic acid) are unlikely to be implicated because they fail to induce relaxant response in the aorta. We cannot exclude that ellagic acid might participate in the endothelial-dependent relaxation of CPC by potentiating the action of other compounds through its antioxidant capacity. Finally, we could not exclude that unidentified compounds, present in CPC, mediated the capacity of $\mathrm{CPC}$ to increase endothelial NO production.

Here we demonstrate that $\mathrm{BK}$ and $\mathrm{CPC}$ acted synergistically to enhance endothelial NO production. Moreover, both compounds probably mediate their effect via distinct pathways at least with regard to the activation of enzymes that promote $\mathrm{O}_{2}^{-}$production such as NADPH oxidase and xanthine oxidase. Although, the mechanism by which BK promote NO release within endothelial cells is well described (see above), that of CPC requires further investigations. It is interesting to note that the mechanism by which CPC mediates its effect does not involve ROS system. Nevertheless, we report here that the potentiating effect of CPC on BK-induced NO release probably plays a role in the vascular protection induced by compounds in Cognac.

In conclusion, the present study elucidates on the synergistic effect of CPC and BK in inducing NO production in human endothelial cells. The data underscore the ability of $\mathrm{BK}$ to stimulate not only NADPH oxidase- but also xanthine oxidase-inhibitor sensitive mechanisms that reduce its efficiency in increasing $\mathrm{NO}$ either alone or in the presence of $\mathrm{CPC}$ as well.

\section{Conflict of Interest}

There is no conflict of interest.

\section{Acknowledgements}

This work was supported in part by grants from Fonds Européen pour le Développement Régional (R.A. $\mathrm{n}^{\circ}$ 8891). MHA is a recipient of doctoral fellowship from the Conseil Régional du Pays de la Loire.

\section{References}

AGOUNI A, LAGRUE-LAK-HAL AH, DUCLUZEAU PH, MOSTEFAI HA, DRAUNET-BUSSON C, LEFTHERIOTIS G, HEYMES C, MARTINEZ MC, ANDRIANTSITOHAINA R: Endothelial dysfunction caused by circulating microparticles from patients with metabolic syndrome. Am J Pathol 173: 1210-1219, 2008.

ANDRIAMBELOSON E, MAGNIER C, HAAN-ARCHIPOFF G, LOBSTEIN A, ANTON R, BERETZ A, STOCLET JC, ANDRIANTSITOHAINA R: Natural dietary polyphenolic compounds cause endothelium-dependent vasorelaxation in rat thoracic aorta. $J$ Nutr 128: 2324-2333, 1998.

ANDRIANTSITOHAINA R: Regulation of vascular tone by plant polyphenols: role of nitric oxide. Gen Physiol Biophys 18 (Suppl 1): 3-5, 1999. 
BAE SW, KIM HS, CHA YN, PARK YS, JO SA, JO I: Rapid increase in endothelial nitric oxide production by bradykinin is mediated by protein kinase A signaling pathway. Biochem Biophys Res Commun 306: 981-987, 2003.

BOULANGER C, SCHINI VB, MONCADA S, VANHOUTTE PM: Stimulation of cyclic GMP production in cultured endothelial cells of the pig by bradykinin, adenosine diphosphate, calcium ionophore A23187 and nitric oxide. Br J Pharmacol 101: 152-156, 1990.

BUSSE R, FLEMING I: Vascular endothelium and blood flow. Handb Exp Pharmacol 176 (Pt2): 43-78, 2006.

CAI H, LI Z, DIKALOV S, HOLLAND SM, HWANG J, JO H, DUDLEY SC, JR, HARRISON DG: NAD(P)H oxidase-derived hydrogen peroxide mediates endothelial nitric oxide production in response to angiotensin II. J Biol Chem 277: 48311-48317, 2002.

DUARTE J, ANDRIAMBELOSON E, DIEBOLT M, ANDRIANTSITOHAINA R: Wine polyphenols stimulate superoxide anion production to promote calcium signaling and endothelial-dependent vasodilatation. Physiol Res 53: 595-602, 2004.

FLEMING I, MICHAELIS UR, BREDENKOTTER D, FISSLTHALER B, DEHGHANI F, BRANDES RP, BUSSE R: Endothelium-derived hyperpolarizing factor synthase (cytochrome P450 2C9) is a functionally significant source of reactive oxygen species in coronary arteries. Circ Res 88: 44-51, 2001.

JAIMES EA, SWEENEY C, RAIJ L: Effects of the reactive oxygen species hydrogen peroxide and hypochlorite on endothelial nitric oxide production. Hypertension 38: 877-883, 2001.

KITAYAMA J, KITAZONO T, IBAYASHI S, WAKISAKA M, WATANABE Y, KAMOUCHI M, NAGAO T, FUJISHIMA M: Role of phosphatidylinositol 3-kinase in acetylcholine-induced dilatation of rat basilar artery. Stroke 31: 2487-2493, 2000.

MARRERO MB, VENEMA VJ, JU H, HE H, LIANG H, CALDWELL RB,VENEMA R: Endothelial nitric oxide synthase interactions with G-protein-coupled receptors. Biochem J 343: 335-340, 1999.

MARTIN S, ANDRIAMBELOSON E, TAKEDA K, ANDRIANTSITOHAINA R: Red wine polyphenols increase calcium in bovine aortic endothelial cells: a basis to elucidate signalling pathways leading to nitric oxide production. Br J Pharmacol 135: 1579-1587, 2002.

MONCADA S, BOLANOS JP: Nitric oxide, cell bioenergetics and neurodegeneration. J Neurochem 97: 1676-1689, 2006.

MONCADA S, HIGGS EA: Nitric oxide and the vascular endothelium. Handb Exp Pharmacol 176 (Pt 1): 213-254, 2006.

NDIAYE M, CHATAIGNEAU M, LOBYSHEVA I, CHATAIGNEAU T, SCHINI-KERTH VB: Red wine polyphenol-induced, endothelium-dependent NO-mediated relaxation is due to the redox-sensitive PI3kinase/Akt-dependent phosphorylation of endothelial NO-synthase in the isolated porcine coronary artery. FASEB J 19: 455-457, 2005.

NIE L, WISE ML, PETERSON DM, MEYDANI M: Avenanthramide, a polyphenol from oats, inhibits vascular smooth muscle cell proliferation and enhances nitric oxide production. Atherosclerosis 186: 260-266, 2006.

RALAY RANAIVO H, DIEBOLT M, SCHOTT C, ANDRIANTSITOHAINA R: Polyphenolic compounds from Cognac induce vasorelaxation in vitro and decrease post-ischaemic cardiac infarction after an oral administration. Fundam Clin Pharmacol 18: 331-338, 2004.

RANDRIAMBOAVONJY V, FLEMING I: Endothelial nitric oxide synthase (eNOS) in platelets: how is it regulated and what is it doing there? Pharmacol Rep 57 (Suppl): 59-65, 2005.

SCHINI-KERTH VB: Dual effects of insulin-like growth factor-I on the constitutive and inducible nitric oxide (NO) synthase-dependent formation of NO in vascular cells. J Endocrinol Invest 22: 82-88, 1999.

SCHNEIDER JC, EL KEBIR D, CHEREAU C, LANONE S, HUANG XL, DE BUYS ROESSINGH AS, MERCIER JC, DALL'AVA-SANTUCCI J, DINH-XUAN AT: Involvement of $\mathrm{Ca}^{2+} /$ calmodulin-dependent protein kinase II in endothelial NO production and endothelium-dependent relaxation. Am J Physiol Heart Circ Physiol 284: H2311-2319, 2003.

STOCLET JC, KLESCHYOV A, ANDRIAMBELOSON E, DIEBOLT M, ANDRIANTSITOHAINA R: Endothelial no release caused by red wine polyphenols. J Physiol Pharmacol 50: 535-540, 1999. 
TRAN QK, WATANABE H, LE HY, YANG J, TAKEUCHI K, KADOMATSU K, MURAMATSU T, OHASHI K: Midkine inhibits bradykinin-stimulated $\mathrm{Ca}^{2+}$ signaling and nitric oxide production in endothelial cells. Biochem Biophys Res Commun 276: 830-836, 2000.

VILLALOBO A: Nitric oxide and cell proliferation. FEBS J 273: 2329-2344, 2006.

ZHANG X, LI H, JIN H, EBIN Z, BRODSKY S, GOLIGORSKY MS: Effects of homocysteine on endothelial nitric oxide production. Am J Physiol 279: F671-F678, 2000. 